\title{
THE VERBAL SYSTEM OF CLASSICAL HEBREW IN THE JOSEPH STORY: \\ AN APPROACH FROM DISCOURSE ANALYSIS1
}

\author{
Yoshinobu Endo
}

\section{Introduction}

The present study investigates the function of the verbal forms in biblical Hebrew prose, using the Joseph story (Gen. 37-50) as a corpus, examining word order, tense, aspect, clause type, sequentiality, and related matters.

The thesis treats direct discourse and narrative separately. It begins by investigating direct discourse, because of its possible resemblance to real speech (chs. 2-6) and then applies the results of this study to narrative (chs. 7-8). While no major functional distinction between direct discourse and narrative can be observed, in the former there is a greater variety of verbal forms (e.g. modal, hortatory forms, etc.) and more freestanding verbal forms. Chapter 8 examines both main and subordinate clauses.

The thesis begins with an examination of one-clause verbal utterances in direct discourse, followed by utterances of two or more clauses. In the case of one-clause verbal utterances (ch. 2) we discuss several issues related to translation into English, and concentrate on the factors which influence the choice of verbal form within a single clause/sentence. This provides a basis for what follows in subsequent chapters, where syntactic interaction with adjacent clauses is considered. Hortatory clauses are examined separately in Chapter 6.

\section{Word Order, Tense and Aspect}

The verbal form may appear either in clause-initial position (øQATAL/ø-YIQTOL) or non-clause-initial position $(x-$ QATAL/x-YIQTOL) without any temporal/aspectual differ-

${ }^{1}$ Yoshinobu Endo, The Verbal System of Classical Hebrew in the Joseph Story: an Approach from Discourse Analysis (Unpublished Ph.D thesis, Bristol, 1993). The supervisors for the thesis were Dr. G.J. Wenham and Prof. J.C.L. Gibson. 
ence. Thus the position of the verb does not seem to affect the function of the conjugation. Rather, the fronting of a constituent of the clause seems to function as a topicalisation, placing it in a position of informational prominence or indicating a topicswitching function (i.e. topic-discontinuity).

The conjugations in biblical Hebrew do not distinguish between perfect and simple past or between future, modal and present. Such distinctions entirely depend on the context or the inherent lexical meaning of the word. However, the distinction between QATAL (Past) and YIQTOL (Non-Past) can clearly be drawn, particularly in the free-standing conjugations, except for stative verbs, verbs with a stative sense, passive constructions, and some other cases. We may also distinguish the conjugations on the basis of the traditional aspectual opposition Complete vs. Incomplete (this is preferable to the opposition Perfective vs. Imperfective suggested by Comrie and others). Thus: QATAL (Complete) and YIQTOL (Incomplete). There may not be much difference between these oppositions in describing the function of, particularly, the free-standing conjugations. A state of affairs which is complete can be viewed as past, one which is incomplete can be viewed as either present or future.

\section{Sequentiality and Non-Sequentiality}

Although the temporal distinction Past/Non-Past and the aspectual opposition Complete/Incomplete works in the freestanding conjugations, neither distinction helps us to explain the functional difference between YIQTOL and (wd)QATAL in the non-past context, between QATAL and (waY)YIQTOL in the past context, or between the IMPV forms and (w)QATAL in the hortatory context. However the functional opposition Non-Sequential vs. Sequential, which is based on an aspectual contrast Stable vs. Unstable, can be applied to the conjugations as follows: in the past context, QATAL (Non-Sequential) and (waY)YIQTOL (Sequential); in the non-past context YIQTOL (Non-Sequential) and (wว)QATAL (Sequential); in the hortatory context Imperative/Jussive/Cohortative (Non-Sequential) and (wว)QATAL (Sequential).

The parameter of sequentiality and non-sequentiality is purely syntactical, relating to the flow of the story as a discourse function: the non-sequential form stops the flow of the 
story, whereas the sequential form lets the story flow on. The latter function should clearly be distinguished from that of the conjunction. The conjunction looks back to the preceding clause, while the sequential form looks forward to the next clause. Thus, the non-sequential form (which may include the participle and other nominal clauses) is often used to describe or depict an action or a state by a single statement. On the other hand, the sequential form is usually employed to narrate a series of actions or situations as a unit by forming a sequence with other sequential forms. This unit may be either a literary (i.e., semantically self-contained) unit or part of such a unit (a topic or theme, a sentence of dialogue or narrative, and the like). While the non-sequential form often appears as a freestanding form, the sequential form more naturally appears in a compound sentence.

Terms such as 'temporal/logical succession', 'consequence', or 'explanation', which are used to describe the function of the sequential forms themselves by Joüon, Waltke \& $\mathrm{O}^{\prime}$ Connor and others, are not adequate. At the semantic level of a discourse containing only sequential forms one can observe not only simple succession, but also simultaneous actions, antithetical links, etc. Also these terms do not cover the sequential form which has no preceding clause, standing in discourseinitial position. Temporal/logical succession, consequence, explanation, and so on, are marked simply by the context in which the forms occur.

\section{Composition of Hebrew Verbal Utterances}

In addition to the above mentioned simple cases (i.e. a single statement depicted by the non-sequential form; a series of actions/situations as a unit traced by the sequential forms), the thread of discourse in biblical Hebrew may contain other combinations of the sequential clause and the non-sequential clause, which may be observed in any temporal context:

(1) Non-Sequential form (often as a circumstantial clause/a semantic stepping stone) $\rightarrow$ Sequential form(s), whose relation is usually either antithetical or logically and/or temporally successive.

(2) Sequential form(s) $\rightarrow$ Non-Sequential form (often as a goal/full stop clause), whose relation is also basically either antithetical or logically and/or temporally successive; 
(3) Combination: Non-Sequential form (often as a circumstantial clause/a semantic stepping stone) $\rightarrow$ Sequential form(s) $\rightarrow$ NonSequential form (as a goal/full stop clause);

(4) Sequential form(s) $\rightarrow$ feither form (as a literary insertion or interpolation) $\} \rightarrow$ Sequential form(s), etc.

Note here that when the non-sequential form is employed, for instance, as a circumstantial clause, it does not mean that the form itself indicates background information (e.g. circumstance, setting, explication, etc.); rather, the nonsequential form creates a pause in the flow of the story which is effectively utilised to discriminate between clauses which are intended to fulfil different functions in the discourse. This is supported by even sequential forms (e.g., waYIQTOL) being employed not for the main line of the story, but for the background information.

Moreover, each form may play an opposite role for the purpose of special literary effects: if the non-sequential forms are used to form a sequence (e.g., in asyndeton), it may produce an effect of vividness or the like; the sequential form may appear as a 'pseudo-independent form', which could be employed for the purpose of producing a literary reverberation (e.g. fade-out; 'foreshadowing', etc.).

\section{Background vs. Foreground}

So far as the 'backgrounding'/'foregrounding' theory (Niccacci, Longacre, et. al) is concerned, this distinction does not seem to be a determinative factor for the choice of the verbal forms. This distinction seems to be a secondary phenomenon or a byproduct of the distinction between sequentiality and nonsequentiality. In fact, foreground information tends to be described with a chain of actions, and one could observe that even sequential forms (e.g. waYYIQTOL) may be employed not for the main line of the story, but for background information.

\section{Tense in the Subordinate / Relative Clause}

A verbal form in the subordinate clause is chosen not from the viewpoint of the narrator, but from that of the immediate participant in the main clause. This is a natural consequence of the principle of economy in a language which has no auxiliary. 
From the viewpoint of the immediate participant in the main clause, subordinate clauses introduced by $ן$, עד have a non-past time reference, whereas that introduced by אחרי has a past time reference. Therefore the non-past form (YIQTOL, etc.) is usually selected for the former and the past form (QATAL, etc.) for the latter. 